\title{
Dental Age in Precocious and Delayed Puberty Periods
}

\author{
Derya Tabakcilar ${ }^{1, \odot ~ R u v e y d e ~ B u n d a k ~}{ }^{2}$ Koray Gencay ${ }^{3}$
}

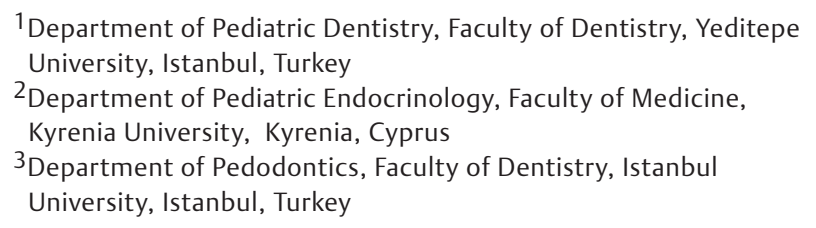

Address for correspondence Derya Tabakcilar, DDS, PhD, Department of Pediatric Dentistry, Faculty of Dentistry, Yeditepe University, Bagdat Street. No. 238 Kadikoy, Istanbul, Turkey (e-mail: derya.tabakcilar@yeditepe.edu.tr).

Eur J Dent 2021;15:539-545

\begin{abstract}
Keywords

- precocious puberty

- delayed puberty

- dental age estimation

- Demirjian method

- panoramic

radiographs

Objectives Precocious puberty indicates quick growth inception and delayed puberty indicates retardation in growth. This study aimed to investigate whether dental development is synchronous with somatic development.

Materials and Methods In this study, 62 girls and 34 boys with precocious puberty aged 5 to 9,29 girls with delayed puberty aged 13 to 16 , and 43 boys with delayed puberty aged 14 to $17 ; 169$ children (91 girls and 78 boys) with normal development were compared about their dental ages through their panoramic radiographs by using the Demirjian method and skeletal ages from hand-wrist radiographs by using Greulich-Pyle atlas.

Results The findings showed that, in all cases, the dental age values were higher than chronologic and skeletal age values to a statistically significant degree. In the precocious puberty group, the dental age values were higher than chronologic age values to a statistically significant degree. In the delayed puberty group, the difference determined between the chronological age and the dental age was not found to be statistically significant.

Conclusion Given that the Demirjian method is inclined to make calculations that are higher than the chronological age, our findings suggest that the dental development was faster in the precocious puberty group and retarded in the delayed puberty group.
\end{abstract}

\section{Objectives}

Puberty is defined as the period in which primary gender properties (gonad and genital structures) and secondary gender properties (such as the development of breasts and hairing in the pubic area in girls; rough voice and increasing testicle volume in boys) are observed, and the ability of reproduction is gained. ${ }^{1}$
The definition of precocious puberty (PP) is diagnosed with the observance of puberty symptoms before the age of eight in girls and before the age of nine in boys. ${ }^{2}$ As a result of the precocious development of secondary gender characteristics, increasing height, further skeletal age, and precocious completion of growth, some problems like shortness and various psychological problems may be present. ${ }^{3}$ In addition,
DOI https://doi.org/

$10.1055 / \mathrm{s}-0041-1726156$

ISSN 1305-7456.

\footnotetext{
(C) 2021. European Journal of Dentistry.

This is an open access article published by Thieme under the terms of the Creative Commons Attribution-NonDerivative-NonCommercial-License, permitting copying and reproduction so long as the original work is given appropriate credit. Contents may not be used for commercial purposes, or adapted, remixed, transformed or built upon. (https://creativecommons.org/licenses/by-nc-nd/4.0/)

Thieme Medical and Scientific Publishers Pvt. Ltd., A-12, 2nd Floor, Sector 2, Noida-201301 UP, India
} 
precocious puberty defined as the two standard deviations below the puberty baseline mean age for a population of children. ${ }^{4}$

Delayed puberty (DP) is the lack of secondary symptoms despite the completion of 13 years of age in girls and 14 years of age in boys. Generally, there is a family history in this circumstance, and unlike precocious puberty, it is observed more in boys than in girls. ${ }^{5}$ It is possible that 2- to 4-year retardations are observed in periods close to puberty in skeletal ages of children with DP. ${ }^{6}$

Accurate determination of dental age is particularly important for clinical dentists, especially pediatric dentists and orthodontists in the treatment of occlusions that change with maxillofacial growth. Knowing the amount and timing of active growth in the craniofacial area facilitates the planning of the treatment. ${ }^{7}$ As well as the dentists, the concept of dental age and atlas, which defines the identification, is also frequently used in the field of forensics. ${ }^{8}$

As reported previously, teeth may be used easily in age prediction since they are not affected much by external factors. ${ }^{9}$ On the other hand, it was also claimed that the data received from dental growth order provides the most accurate results due to the hard structure and low metabolisms when compared with the other hard tissue structures in the organism. ${ }^{10}$

Demirjian, Goldstein, and Tanner introduced the dental age estimation method that is based on the radiological assessment of the seven teeth in the left mandibula in Canadian children from French origin in $1973 .{ }^{11}$ The Demirjian method (DM) is based on a simple orthopantomogram and ensures repeatability intra- and inter-examinations with a reliable standardization. One of the reasons that this method has been widely accepted is the universality of the maturation scoring system, and the possibility of achieving equivalent dental age when compared with different societies and when it is applied with small local samples. ${ }^{12}$

The present study aims to examine how dental maturation is affected in case the systemic precocious or delayed development occurs. Our hypothesis was that the tooth maturity in children with early and delayed puberty differs significantly from children with normal growth.

\section{Materials and Methods}

In this study, the medical records of 5- to 8-year-old 62 girls with PP, 5- to 9-year-old 34 boys with PP, 13- to 16-year-old 29 girls with DP, and 14- to 17 -year-old 43 boys with DP, who were diagnosed with the tests (skeletal age determined with plasma luteinizing hormone and follicle stimulating hormone estradiol values, left-hand wrist X-ray; pelvic ultrasound in girls and testis palpation in boys, karyotype analysis, and magnetic resonance imaging) performed at Istanbul University, Faculty of Medicine, Department of Child Health and Childhood Diseases, Growth, Development and Pediatric Endocrinology Policlinics, who did not receive any medication, were examined by using the panoramic X-rays.
In addition, the archive records of 169 healthy children (91 girls and 78 boys), who applied to Istanbul University, Faculty of Dentistry, Pedodontics Department and did not have any systemic diseases within the same age range, were examined.

The dentition durations and developments were examined by using the digital panoramic radiographs (DPR) according to the ages of the children, and the dental ages were determined. The routine DPR of the patients (in the faculty of dentistry) that were diagnosed with precocious and delayed puberty in the faculty of medicine, and the routine DPR of the control patients in the faculty of dentistry was used in this study. Since the present study was retrospective, only the archive records were examined and no new DPRs were taken. Skeletal ages of PP and DP groups were measured by using the Greulich-Pyle atlas (GRP) in the medical school.

\section{The Collection of the Data}

In the scope of the study, the Helsinki Declaration was applied and permission was received from Faculty of Dentistry, Ethical Board, Istanbul University (protocol no: 2015/55).

The DPRs that were not clear for the examinations, which had missing teeth due to traumas or diseases, received root canal treatment, had pathological teeth structure, and had chronic disease histories, were excluded from this study.

The children in the control group were selected from among the healthy children who did not have any syndromic or systemic diseases, and gender and age of the control and study groups were matched.

Since standardization was not possible in the control group, the skeletal age values were not examined. As the study was retrospective, the skeletal age values in the other groups had been recorded previously. If the observers were different, the standardization would be disrupted.

For chronological age, decimal age was calculated based on the dates when panoramic radiographs were taken and on the dates of births of the patients.

\section{Dental Age Analysis Using the Demirjian Method from Panoramic Radiography}

The DPRs were taken in the Istanbul University, Faculty of Dentistry with Planmeca Proline PM Device. Each tooth was examined by concerning eight calcification stages $(\mathrm{A}-\mathrm{H})$ with completed criteria in the original technique. Following the determination of the developmental stages of the assessed teeth, the dental development scores of each tooth were calculated by referring to the tables given in the Demirjian system for boys and girls.

\section{The Reliability of the Measurements}

In this study, 40 DPRs, which were selected randomly after 1 week of the measurements, were scored again twice by the same observer (D.T.). The agreement level among 1 to 2,1 to 3 , and 2 to 3 observations was 1.000 (intraclass correlation coefficient [ICC; \%95 GA]: 1.000 [1.000-1.000], $p<0.001$ ). Besides, the agreement level among the three observations was determined as 1.000 (ICC [\%95 GA]: 1.000 [1.000-1.000], $p<0.001$ ). 


\section{Statistical Analysis}

Based on previous findings reported by Gaethofs, ${ }^{13}$ as a result of power analysis using the GPower 3.1.9.4. program, indicated that a minimum of 27 samples per group was required to detect a significant difference between groups when $\alpha$ is set at 0.05 and Power: 0.80 (effect size: 0.2074089 ) of the study (the numbers of boys and girls in the control group were also taken equally with the other groups). Statistical analyses were performed by using Number Cruncher Statistical System 2007 (Kaysville, Utah, United States). Data were reported as a minimum, maximum, mean, standard deviation, frequency, and percentage. Differences between dental age, skeletal age, and chronological age were analyzed by using the paired $t$-test. Associations among ages were reported with Pearson's correlation coefficients. Concordance among observations was tested with ICC. A $p$-value of $<0.05$ was considered statistically significant.

\section{Results}

The descriptive properties of the study are presented in - Table 1. In this context, this study was conducted with 336 cases. In total, $54.2 \%$ of the cases $(n=182)$ were girls, and $45.8 \%$ of them $(n=154)$ were boys. The chronological ages of the cases varied between 4.64 and 16.45, and it was $9.93 \pm 3.93$ on average.

The assessment of the level of the correlation between the chronological and dental age difference concerning gender according to the dependent groups $t$-test is given in - Table 2. In this context, in all of the control group and PP group, and in all of the boys and girls, it was determined that the chronological age values were lower than the DM dental age values at a statistically significant level $(p<0.001)$.
In DP group, in boys the chronological age values were found to be lower than the DM dental age values at a statistically significant level. Except for the DP group girls, a positive relation was detected between the chronological age and dental age in all groups. There was a positive correlation between chronological age and DM dental age in all groups except for DP group girls, according to independent groups $t$-test.

The assessment of the correlation and difference level between the chronological age and GRP skeletal age according to gender variable in dependent groups $t$-test is given in - Table 3. In the PP group, girls, boys and in the whole group, it was determined that the chronological age values were lower than the GRP skeletal age values at a statistically significant level. In the DP group, girls, boys and in the whole group, it was detected that the GRP skeletal age values were lower than chronological age values at a statistically

Table 1 Distribution of descriptive data

\begin{tabular}{|l|l|l|l|}
\hline \multicolumn{2}{|l|}{} & $\begin{array}{l}\text { Minimum- } \\
\text { Maximum }\end{array}$ & Mean \pm SD \\
\hline Chronological age & $4.64-16.45$ & $9.93 \pm 3.93$ \\
\hline \multicolumn{2}{|l|}{ GRP skeletal age $(n=168)$} & $5.66-15.40$ & $9.95 \pm 2.75$ \\
\hline \multicolumn{2}{|l|}{ DM dental age } & $5.17-17.11$ & $10.54 \pm 3.65$ \\
\hline \multirow{3}{*}{ Gender } & Girls & $n$ & $\%$ \\
\cline { 2 - 4 } & Boys & 182 & 54.2 \\
\hline \multirow{3}{*}{ Group } & Control & 154 & 45.8 \\
\cline { 2 - 4 } & Precocious puberty & 168 & 50.0 \\
\cline { 2 - 4 } & Delayed puberty & 72 & 28.6 \\
\hline
\end{tabular}

Abbreviations: DM, The Demirjian method; SD, standard deviation.

Table 2 Assessment of difference between the chronological age and DM dental age according to gender in groups

\begin{tabular}{|c|c|c|c|c|c|c|c|c|}
\hline & \multirow{2}{*}{$\begin{array}{l}\text { Chronological } \\
\text { age } \\
\text { Mean } \pm \text { SD } \\
\end{array}$} & \multirow{2}{*}{$\begin{array}{l}\text { DM dental } \\
\text { age } \\
\text { Mean } \pm \text { SD } \\
\end{array}$} & \multirow{2}{*}{$\begin{array}{l}\text { Difference } \\
\text { Mean } \pm \text { SD }\end{array}$} & \multirow{3}{*}{$\begin{array}{l}\mathrm{t} \\
-27.896\end{array}$} & \multirow{3}{*}{$\begin{array}{l}p-\text { Value }^{\mathrm{a}} \\
<0.001^{\mathrm{b}}\end{array}$} & \multirow{3}{*}{$\begin{array}{l}\mathbf{r} \\
0.999\end{array}$} & \multirow{3}{*}{$\begin{array}{l}p \text {-Value } \\
<0.001^{\text {b }}\end{array}$} \\
\hline & & & & & & & & \\
\hline Control & Girls & $8.85 \pm 3.43$ & $9.37 \pm 3.46$ & $-0.51 \pm 0.18$ & & & & \\
\hline group & Boys & $11.21 \pm 4.21$ & $11.7 \pm 4.15$ & $-0.49 \pm 0.18$ & -24.463 & $<0.001^{\mathrm{b}}$ & 0.999 & $<0.001^{b}$ \\
\hline & General & $9.93 \pm 3.97$ & $10.44 \pm 3.96$ & $-0.50 \pm 0.17$ & -37.126 & $<0.001^{\mathrm{b}}$ & 0.999 & $<0.001^{b}$ \\
\hline & $p$-Value & & & & -0.833 & 0.406 & & \\
\hline Precocious & Girls & $6.71 \pm 0.80$ & $8.02 \pm 0.73$ & $-1.31 \pm 0.74$ & -13.914 & $<0.001^{\mathrm{b}}$ & 0.532 & $<0.001^{b}$ \\
\hline puberty & Boys & $6.49 \pm 0.92$ & $7.87 \pm 1.13$ & $-1.39 \pm 0.87$ & -9.322 & $<0.001^{\mathrm{b}}$ & 0.661 & $<0.001^{b}$ \\
\hline & General & $6.63 \pm 0.85$ & $7.97 \pm 0.89$ & $-1.34 \pm 0.78$ & -16.700 & $<0.001^{\mathrm{b}}$ & 0.592 & $<0.001^{b}$ \\
\hline & $p$-Value & & & & 0.450 & 0.654 & & \\
\hline Delayed & Girls & $13.67 \pm 0.72$ & $13.25 \pm 1.96$ & $0.42 \pm 1.84$ & 1.219 & 0.233 & 0.338 & 0.073 \\
\hline puberty & Boys & $14.75 \pm 0.49$ & $14.86 \pm 0.49$ & $-0.11 \pm 0.02$ & -35.214 & $<0.001^{\mathrm{b}}$ & 0.999 & $<0.001^{b}$ \\
\hline & General & $14.31 \pm 0.79$ & $14.21 \pm 1.51$ & $0.10 \pm 1.19$ & 0.731 & 0.467 & 0.628 & $<0.001^{b}$ \\
\hline & $p$-Value & & & & 1.541 & 0.135 & & \\
\hline General & Girls & $8.89 \pm 3.38$ & $9.53 \pm 3.12$ & $-0.64 \pm 1.03$ & -8.322 & $<0.001^{\mathrm{b}}$ & 0.953 & $<0.001^{b}$ \\
\hline & Boys & $11.15 \pm 4.18$ & $11.74 \pm 3.87$ & $-0.58 \pm 0.62$ & -11.606 & $<0.001^{\mathrm{b}}$ & 0.991 & $<0.001^{b}$ \\
\hline & $p$-Value & & & & -0.573 & 0.567 & & \\
\hline
\end{tabular}

Abbreviations: DM, The Demirjian method; SD, standard deviation.

aDependent groups $t$-test.

${ }^{\mathrm{b}} \mathrm{p}<0.01$.

Note: $r$ denotes Pearson's correlation coefficient. 
Table 3 Assessment of difference between the chronological age and GRP skeletal age according to gender in groups

\begin{tabular}{|c|c|c|c|c|c|c|c|c|}
\hline & $\begin{array}{l}\text { Chronological } \\
\text { age }\end{array}$ & $\begin{array}{l}\text { GRP } \\
\text { skeletal age }\end{array}$ & Difference & \multirow[t]{2}{*}{$\mathrm{t}$} & \multirow[t]{2}{*}{$p$-Value ${ }^{c}$} & \multirow[t]{2}{*}{$r$} & \multirow[t]{2}{*}{$p$-Value } \\
\hline & & Mean \pm SD & Mean \pm SD & Mean \pm SD & & & & \\
\hline \multirow{4}{*}{$\begin{array}{l}\text { Precocious } \\
\text { puberty }\end{array}$} & Girls & $6.71 \pm 0.8$ & $7.78 \pm 0.86$ & $-1.06 \pm 0.41$ & -20.406 & $<0.001^{\text {b }}$ & 0.880 & $<0.001^{\mathrm{b}}$ \\
\hline & Boys & $6.49 \pm 0.92$ & $7.61 \pm 0.95$ & $-1.12 \pm 0.12$ & -52.227 & $<0.001^{\mathrm{b}}$ & 0.992 & $<0.001^{\text {b }}$ \\
\hline & General & $6.63 \pm 0.85$ & $7.72 \pm 0.89$ & $-1.09 \pm 0.34$ & -31.395 & $<0.001^{\text {b }}$ & 0.926 & $<0.001^{\text {b }}$ \\
\hline & $p$-Value & & & & 0.985 & 0.328 & & \\
\hline \multirow{4}{*}{$\begin{array}{l}\text { Delayed } \\
\text { puberty }\end{array}$} & Girls & $13.67 \pm 0.72$ & $12.06 \pm 0.79$ & $1.61 \pm 0.60$ & 14.361 & $<0.001^{\mathrm{b}}$ & 0.688 & $<0.001^{b}$ \\
\hline & Boys & $14.75 \pm 0.49$ & $13.53 \pm 0.57$ & $1.22 \pm 0.69$ & 11.623 & $<0.001^{\mathrm{b}}$ & 0.166 & 0.287 \\
\hline & General & $14.31 \pm 0.79$ & $12.94 \pm 0.98$ & $1.38 \pm 0.68$ & 17.218 & $<0.001^{\mathrm{b}}$ & 0.728 & $<0.001^{\mathrm{b}}$ \\
\hline & $p$-Value & & & & 2.446 & $0.017^{\mathrm{a}}$ & & \\
\hline \multirow[t]{3}{*}{ PP and DP } & Girls & $8.93 \pm 3.35$ & $9.14 \pm 2.17$ & $-0.21 \pm 1.34$ & -1.530 & 0.130 & 0.971 & $<0.001^{b}$ \\
\hline & Boys & $11.10 \pm 4.19$ & $10.91 \pm 3.05$ & $0.19 \pm 1.28$ & 1.275 & 0.206 & 0.986 & $<0.001^{\mathrm{b}}$ \\
\hline & $p$-Value & & & & -1.972 & $0.049^{a}$ & & \\
\hline
\end{tabular}

Abbreviations: DM, The Demirjian method; DP, delayed puberty; PB, precocious puberty; SD, standard deviation.

${ }^{\mathrm{a}} \mathrm{p}<0.05$.

${ }^{\mathrm{b}} \mathrm{p}<0.01$.

'Dependent groups $t$-test.

Note: Since the GRP skeletal age was not measured in the control group, the correlation levels and $p$-values given in the relevant lines cover the PP and DP cases.

Table 4 Assessment of difference between the DM dental age and GRP skeletal age according to gender in groups

\begin{tabular}{|c|c|c|c|c|c|c|c|c|}
\hline & $\begin{array}{l}\text { DM dental } \\
\text { age }\end{array}$ & $\begin{array}{l}\text { GRP } \\
\text { skeletal } \\
\text { age }\end{array}$ & Difference & \multirow[t]{2}{*}{$\mathrm{t}$} & \multirow[t]{2}{*}{$p$-Value ${ }^{c}$} & \multirow[t]{2}{*}{$r$} & \multirow[t]{2}{*}{$p$-Value } \\
\hline & & Mean \pm SD & Mean \pm SD & Mean \pm SD & & & & \\
\hline \multirow{4}{*}{$\begin{array}{l}\text { Precocious } \\
\text { puberty }\end{array}$} & Girls & $8.02 \pm 0.73$ & $7.78 \pm 0.86$ & $0.24 \pm 0.78$ & 2.475 & $0.016^{\mathrm{a}}$ & 0.532 & $<0.001^{b}$ \\
\hline & Boys & $7.87 \pm 1.13$ & $7.61 \pm 0.95$ & $0.26 \pm 0.87$ & 1.782 & 0.084 & 0.669 & $<0.001^{\mathrm{b}}$ \\
\hline & General & $7.97 \pm 0.89$ & $7.72 \pm 0.89$ & $0.25 \pm 0.81$ & 3.061 & $0.003^{b}$ & 0.592 & $<0.001^{\mathrm{b}}$ \\
\hline & $p$-Value & & & & -0.116 & 0.908 & & \\
\hline \multirow{4}{*}{$\begin{array}{l}\text { Delayed } \\
\text { puberty }\end{array}$} & Girls & $13.25 \pm 1.96$ & $12.06 \pm 0.79$ & $1.19 \pm 1.92$ & 3.339 & $0.002^{\mathrm{b}}$ & 0.253 & 0.186 \\
\hline & Boys & $14.86 \pm 0.49$ & $13.53 \pm 0.57$ & $1.33 \pm 0.69$ & 12.547 & $<0.001^{\mathrm{b}}$ & 0.156 & 0.319 \\
\hline & General & $14.21 \pm 1.51$ & $12.94 \pm 0.98$ & $1.27 \pm 1.32$ & 8.191 & $<0.001^{\mathrm{b}}$ & 0.508 & $<0.001^{\mathrm{b}}$ \\
\hline & $p$-Value & & & & -0.383 & 0.704 & & \\
\hline \multirow[t]{3}{*}{ PP and DP } & Girls & $9.69 \pm 2.75$ & $9.14 \pm 2.17$ & $0.55 \pm 1.32$ & 3.934 & $<0.001^{b}$ & 0.881 & $<0.001^{b}$ \\
\hline & Boys & $11.77 \pm 3.59$ & $10.91 \pm 3.05$ & $0.86 \pm 0.94$ & 8.060 & $<0.001^{b}$ & 0.973 & $<0.001^{b}$ \\
\hline & $p$-Value & & & & -1.749 & 0.082 & & \\
\hline
\end{tabular}

Abbreviations: DM, The Demirjian method DP, delayed puberty; PB, precocious puberty; SD, standard deviation.

${ }^{\mathrm{a}} \mathrm{p}<0.05$.

${ }^{\mathrm{b}} p<0.01$.

'Dependent groups t-test.

Note: Since the skeletal age was not measured in the control group, the correlation levels and $p$-values given in the relevant lines cover the precocious puberty and delayed puberty cases.

significant level. In the DP group, it was determined that the difference between chronological age and GRP skeletal age in girls was higher than that of the boys at a statistically significant level. In the PP and DP groups, in girls there was a difference between the visible chronological age and GRP skeletal age $-0.21 \pm 1.34$ on average, and in boys, this difference was $0.19 \pm 1.28$ on average. It was also determined that the difference between the chronological age and GRP skeletal age was significant at a statistical level both in girls and boys. Except for DP group boys, in all groups, there was a positive relationship between the chronological age and GRP skeletal age. Independent groups $t$-test showed that in all groups, a positive relation was detected between the chronological age and GRP skeletal age.

The assessment of the difference and correlation between the DM dental age and GRP skeletal age in the groups was determined with the dependent groups $t$-test according to the gender variable in - Table 4. In PP group girls and in the whole group, it was observed that the DM dental age values were higher than the GRP skeletal age values at a statistically significant level. In the DP group, girls, boys, and in the whole group, the DM dental age values were higher than the GRP 
skeletal age values at a statistically significant level. In precocious and delayed puberty group girls and boys, the DM dental age values were higher than the GRP skeletal age values at a statistically significant level. In all groups, a positive relation was detected between the DM dental age and GRP skeletal age.

\section{Discussion}

The DM is considered to be an objective method since it contains specially drawn line diagrams and radiographic images and criteria for defining tooth development stages. ${ }^{14}$ In addition, DM values have the highest consistency in repetitive measurements among different researchers. In addition, the developmental stages of the teeth are described in detail in visual and written form. Thus, it eliminates the suspicious evaluations with this way. We have observed good reproducibility among three observations, too, during this study while applying the DM.

Some of the studies in the literature stated that the dental ages were overestimated according to the DM references. ${ }^{15,16}$ Similarly, in our study, the findings showed that the dental age values were higher than the chronologic and skeletal age values at a statistically significant level in all cases. When interpreting the results of this study, the difference shifted from this overestimation is considered.

There are many studies in which the relationship between the dental age that was measured with the DM and the chronological age was investigated. Among these studies, the researches conducted by Borcic et al. ${ }^{17}$ (Croatian), Bagherian and Sadeghi ${ }^{15}$ (Iranian), Bagherpour et al ${ }^{18}$ (Iranian), Hegde et $\mathrm{al}^{19}$ (Belgium), Flood et $\mathrm{al}^{20}$ (South Australian), and Uysal et $\mathrm{al}^{21}$ (Turkish) claimed that this method was applicable clinically in different populations. Since this method is used in the majority of modern studies, the dental age was estimated with DM in this study.

There are some studies in which the DM was used in Turkish children. ${ }^{22-24}$ Tunc and Koyuturk conducted a study in the Northern parts of Turkey, and showed that the dental development in Turkish children was at a further level in girls of 0.50 to 1.44 years and in boys of 0.36 to 1.43 years when compared with the Canadian children of French origin. ${ }^{23}$ Our study has also been applied in the northwestern part of Turkey. As reported in previous studies, DM dental age was found to be higher than chronological age in our study, too.

In a developing child, since chronological age is not a parameter on its own in assessing the development, various skeletal maturation indicators have been developed. Saglam and Gazilerli ${ }^{25}$ have stated that replacing skeletal maturity with dental stages is insufficient and unreliable to predict pubertal growth. However, in the meta-analysis results of Bitterncourt et $a l,{ }^{26}$ a high correlation was found between them. The maturation level of the child may be determined with traditional hand-wrist radiographs. Greulich and Pyle are one of the most popular methods for predicting skeletal age in children. There are many studies in the literature evaluating the applicability of the GP method for the Turkish population. ${ }^{27}$ In our study, the reason for comparing dental age with skeletal age was to compare the biological age indicators of the individual. In addition, skeletal age measurements are used in the indication of precocious and delayed puberty in Turkey. Skeletal age was measured using the GRP atlas in the medical school, where the data of our study were collected. In this study, the findings showed that there is a positive correlation between DM dental age and GRP skeletal age. In all cases of our study, the dental age values were higher than GRP skeletal age in PP and DP groups. As far as we know from previous studies like Santoro et al, ${ }^{28} \mathrm{DM}$ dental age was expected to be calculated more than skeletal age. When evaluating the results, we had to pay attention to this difference in children with PP and DP.

Little is known about the effects of PP on dental development. Some studies have suggested that the hormonal properties can potentially affect tooth sizes at the intrauterine stage. 29,30

The change in the growth of the craniofacial complex and the rate of tooth maturation that may occur in children with PP should be well defined. In this way, it will be possible to provide effective treatment in time to improve skeletal and dental incompatibilities. As the potential effects of the PP on dentofacial and development, it could be expected a breakdown on the maturation of the dental arches, leading to an increased risk of dental crowding and changes in facial balance. $^{31}$

In the literature, there are few studies in which the dental age values are examined in children with PP. To our knowledge, there is no study has investigated the potential impacts of early body maturation of both girls and boys with PP on dental maturation. Previous studies have reported a relationship between tooth maturity and chronological and skeletal age. $^{32,33}$ The findings of our study showed a strong positive correlation between dental maturation and chronological age and skeletal age.

In a study of 101 children with idiopathic PP, it was observed that the dental age was significantly lower than the chronological age, and the skeletal age was significantly higher than the chronological age. ${ }^{34}$ However, Lee et al observed that all the mandibular teeth of the central precocious puberty girls were more mature than girls with normal development..$^{32}$ In our study, dental age values were found to be higher in the PP and DP groups compared with the chronological age, but this difference was higher in the PP group. According to these results, we can state that the dental maturation is faster in children with PP.

Lee et al showed a strong positive correlation between the tooth formation stages of mandibular teeth and the presence of PP in girls and increased skeletal age. ${ }^{32}$ Baik et al revealed that a higher DM dental age value is associated with higher chronological age and skeletal age, and the difference between dental age, chronological age and skeletal age is statistically significant..$^{33}$ Similarly, in our study, DM dental age values were found to be statistically significantly higher than skeletal age values. In previous studies, the sample group consisted of girls, but in our study, the results included both girls and boys. According to these results, in early adolescent children, we can say that the dental maturation is faster than skeletal maturation. In early adolescent children, it will be 
beneficial to pay attention to this situation at the beginning of the orthodontic treatment.

The most common cause of DP is structural growth and the delay in secondary characters not starting. They are typically healthy children and have shortness of age and puberty delay according to the chronological age, but this delay is compatible with skeletal age. ${ }^{35}$ As expected in our study, chronological age values were found to be statistically significantly higher than GRP skeletal age values.

To our knowledge, there are a few studies on boys with DP, but no studies on girls with DP have been published. However, there is a study conducted in girls with menstrual disorders in the literature. A significant delay was observed in skeletal maturity and pubertal growth stages in girls with menstrual disorders. ${ }^{36}$

Lewis and Garn and Demirjian reported that the dental maturation was deviated slightly as precocious or late in children with excessive developmental retardation, and they claimed that the mechanisms that controlled dental development were independent of somatic development and/or sexual maturity. ${ }^{37,38}$ However, it has been found that the dental age of patients with familial short stature is delayed according to their chronological age and skeletal age. We should note that these patients did not have a delay in puberty time. ${ }^{39}$

Keller ${ }^{40}$ studied 179 children with various endocrine and metabolic diseases selected for the study from pediatric patients at the Mayo Clinic over a 2-year period. Dental age was delayed in children with the DP, by more than 1.50 standard deviations in 14 of 18 patients and less than 1.00 standard deviations in only one patient. The relationship between skeletal maturation delay and dental maturation delay was inconsistent; however, the dental lag tended to be equal to or higher than the skeletal lag. In addition, it has been stated that the factors other than known hormonal deficiencies may cause a delay in dental maturation. Gaethofs et $\mathrm{al}^{13}$ compared eight boys with DP who were older than 14 years of age and 38 healthy boys with the DM. At the end of the study, they reported that there were significant dental maturation delays in boys with DP. In our study, similarly, chronological age values were lower at a statistically significant level than the dental age values in delayed puberty boys. However, in the delayed puberty group, the difference detected between chronological age and dental age was not found to be statistically significant. We believe that this stems from the high sampling number in our study and the inclusion of the girls with delayed puberty in our study.

The effects of hormonal disorders on the stomatognathic system need to be considered extensively in the field of pediatric dental practice and research. This discovery provides valuable information for clinical practice because child dentists have the opportunity to monitor and/or intervene early in the craniofacial development of children and adolescents. As a result, they can also play an important role in identifying related hormonal disorders.

In this study, because of the retrospective and crosssectional design, skeletal age determination could not be made in the control group. In addition, taking wrist radiographs from the control group could create an ethically suspicious situation. It was quite difficult to reach the panoramic radiography of individuals who had not started hormonal therapy. Thus, prospective studies could not be done. This was the limitation of this study. In addition, there are some methodological deficiencies in our study, since the onset of puberty in precocious puberty is unknown and we cannot equalize the time it has passed. In addition, our study included children who had been diagnosed but had not started treatment. We should note that when these patients start drug treatment, individuals may be affected differently from treatments due to differences in growth and development patterns. It is, therefore, important to know that the results cannot be generalized for clinical practice in people who have started treatment, which emphasizes the need for more clinical trials for longitudinal evaluation of dentofacial development with full evidence to investigate the effects of drug therapy.

\section{Conclusion}

In this descriptive study, preliminary data on dental maturation in both girls and boys with precocious and delayed puberty are shown. When gender is not considered, the difference between chronological age and DM dental age in the control group (in healthy children) was determined to be -0.50 years. This difference was -1.34 in PP group and 0.10 year in DP group. When we consider that the DM is inclined to make calculations that are higher than the chronological age, the results of our study made us think that the dental development was faster in the PP group and retarded in the DP group.

Recently, it was observed that the prevalence of precocious puberty is increasing due to various environmental factors. Based on this, the dentoalveolar development that is faster in children with precocious puberty should not be ignored when assessments are made. In pedodontic and orthodontic treatment planning, this situation must be taken into consideration in terms of timing and prognosis. On the other hand, it was observed that the dental development was not so retarded as somatic development in individuals with delayed puberty. In this context, although there are no drawbacks in the planning in individuals with DP being parallel to healthy children, the individuals should be followed closely in terms of malocclusion development.

\section{Note}

This study was presented in Turkish Dental Association, 23rd International Dental Congress at Istanbul Congress Center, Istanbul, Turkey 21-24 September 2017 (Oral preentation "Comparative Study of Dental Age in Precocious and Delayed Puberty Periods in Children" by D.T., R.B., and K.G.

\section{Funding}

None.

\section{Conflict of Interest}

None declared. 


\section{Acknowledgment}

We would like to thank all the staff members of Department of Child Health and Childhood Diseases, Growth, Development and Pediatric Endocrinology, Faculty of Medicine, Istanbul University for providing the files of patients with precocious and delayed puberty.

\section{References}

1 Patton GC, Viner R. Pubertal transitions in health. Lancet 2007;369(9567): :1130-1139

2 Kaplowitz P, Lawrence S. Precocious puberty: a guide for families. Available at: https://www.aap.org/en-us/Documents/ soen_precocious_puberty.pdf. Accessed 2014

3 Hines CM, Whittier FM, Baker B, Toy EC. The clinical evaluation and treatment of female precocious puberty. Prim Care Update Ob Gyns 2003;10(1):44-50

4 Misra M, Radovick S, Precocious puberty. In: Pediatric Endocrine Disorders; 2014 144-147

5 Kaplowitz P. Delayed puberty in boys: a guide for families. Available at: https://www.aap.org/en-us/Documents/soen_ precocious_puberty.pdf. Accessed 2014

6 Verdonck A, Gaethofs M, Carels C. de Zegher F. Effect of low-dose testosterone treatment on craniofacial growth in boys with delayed puberty. Eur J Orthod 1999;21(2):137-143

7 Bala M, Pathak A, Jain RL. Assessment of skeletal age using MP3 and hand-wrist radiographs and its correlation with dental and chronological ages in children. J Indian Soc Pedod Prev Dent 2010;28(2):95-99

8 Karadayi B, Afsin H, Karadayi S, Ozaslan A. The role and significance of dental development atlas in age estimation. Bull Leg Med 2014;19(2):75-80

9 Karadayi B, Afşin H, Koç S. Radiographic methods used for estimation of dental age in child: a review J Forensic Med 2013;10(2)

10 Karadayi B, Iscan MY. Dental age estimation with demirjian technique on living children in Northwestern Turkey. J Forensic Med 2014;11(2):71-77

11 Demirjian A, Goldstein H. New systems for dental maturity based on seven and four teeth. Ann Hum Biol 1976;3(5): 411-421

12 Priyadarshini C, Puranik MP, Uma SR. Dental age estimation methods : a review. Int J Adv Heal Sci 2015;1(12):19-25

13 Gaethofs M, Verdonck A, Carels C. de Zegher F. Delayed dental age in boys with constitutionally delayed puberty. Eur J Orthod 1999;21(6):711-715

14 Mani SA, Naing L, John J, Samsudin AR. Comparison of two methods of dental age estimation in 7-15-year-old Malays. Int J Paediatr Dent 2008;18(5):380-388

15 Bagherian A, Sadeghi M. Assessment of dental maturity of children aged 3.5 to 13.5 years using the Demirjian method in an Iranian population. J Oral Sci 2011;53(1):37-42

16 Yan J, Lou X, Xie L, Yu D, Shen G, Wang Y. Assessment of dental age of children aged 3.5 to 16.9 years using Demirjian's method: a meta-analysis based on 26 studies. PLoS One 2013;8(12): e84672

17 Borcic I, Petrovecki M, Brkic H. Studies of two different methods for dental age estimation in croatian children. Acta Stomatol Croat 2006;40(2):135-141

18 Bagherpour A, Imanimoghaddam $M$, Bagherpour MR, Einolghozati M. Dental age assessment among Iranian children aged 6-13 years using the Demirjian method. Forensic Sci Int 2010;197(1-3):121.e1-121.e4

19 Hegde RJ, Sood PB. Dental maturity as an indicator of chronological age: radiographic evaluation of dental age in 6 to 13 years children of Belgaum using Demirjian methods. J Indian Soc Pedod Prev Dent 2002;20(4):132-138
20 Flood SJ, Franklin D, Turlach BA, McGeachie J. A comparison of Demirjian's four dental development methods for forensic age estimation in South Australian sub-adults. J Forensic Leg Med 2013;20(7):875-883

21 Uysal T, Sari Z, Ramoglu SI, Basciftci FA. Relationships between dental and skeletal maturity in Turkish subjects. Angle Orthod 2004;74(5):657-664

22 Esenlik E, Atak A, Altun C. Evaluation of dental maturation in children according to sagittal jaw relationship. Eur J Dent 2014;8(1):38-43

23 Tunc ES, Koyuturk AE. Dental age assessment using Demirjian's method on northern Turkish children. Forensic Sci Int 2008; 175(1):23-26

24 Ozveren N, Serindere G. Comparison of the applicability of Demirjian and Willems methods for dental age estimation in children from the Thrace region, Turkey. Forensic Sci Int 2018;285:38-43

25 Sahin Sağlam AM, Gazilerli U. The relationship between dental and skeletal maturity. J Orofac Orthop 2002;63(6):454-462

26 Bittencourt MV, Cericato G, Franco A, Girão R, Lima APB, Paranhos L. Accuracy of dental development for estimating the pubertal growth spurt in comparison to skeletal development: a systematic review and meta-analysis. Dentomaxillofac Radiol 2018;47(4):20170362

27 Gungor OE, Celikoglu M, Kale B, Gungor AY, Sari Z. The reliability of the Greulich and Pyle atlas when applied to a Southern Turkish population. Eur J Dent 2015;9(2):251-254

28 Santoro V, Roca R, De Donno A, et al. Applicability of Greulich and Pyle and Demirijan aging methods to a sample of Italian population. Forensic Sci Int 2012;221(1-3):153.e1-153.e5

29 Dempsey PJ, Townsend GC, Richards LC. Increased tooth crown size in females with twin brothers: evidence for hormonal diffusion between human twins in utero. Am J Hum Biol 1999;11(5):577-586

30 Ribeiro DC, Brook AH, Hughes TE, Sampson WJ, Townsend GC. Intrauterine hormone effects on tooth dimensions. J Dent Res 2013;92(5):425-431

31 de Paula Júnior DF, Mendonça EF, da Costa PSS, Leles CR. Malocclusion and maxillofacial characteristics of young girls having precocious puberty. Int J Paediatr Dent 2018;28(5): 540-546

32 Lee H-K, Choi S-H, Fan D, Jang K-M, Kim M-S, Hwang C-J. Evaluation of characteristics of the craniofacial complex and dental maturity in girls with central precocious puberty. Angle Orthod 2018;88(5):582-589

33 Baik J, Choi J, Kim SJ, Kim JH, Kim S, Kim JH, Predictive value of dental maturity for a positive gonadotropin- releasing hormone stimulation test result in girls with precocious puberty. J Korean Med Sci2017;(21):296-302

34 Roberts MW, Li SH, Comite F, et al. Dental development in precocious puberty. J Dent Res 1985;64(8):1084-1086

35 Aycan Z. Delayed Puberty. Turk Pediatri Ars 2011;46(Suppl 1): 88-91

36 Smaglyuk LV, Liakhovska AV. Skeletal and dental maturity in female adolescents with menstrual disorders. World Med Biol 2019;15(69):153

37 Garn SM, Lewis AB, Kerewsky RS. Genetic, nutritional, and maturational correlates of dental development. J Dent Res 1965;44(1):228-242

38 Demirjian A, Buschang PH, Tanguay R, Patterson DK. Interrelationships among measures of somatic, skeletal, dental, and sexual maturity. Am J Orthod 1985;88(5):433-438

39 Vallejo- Bolanos E, Espana-Lopez AJ. The relationship between dental age, bone age and chronological age in children with short stature. J Pharm Bioallied Sci 5 (Suppl 1): S73-S79

40 Keller EE, Sather AH, Hayles AB. Dental and skeletal development in various endocrine and metabolic diseases. J Am Dent Assoc 1970;81(2):415-419 